\title{
Differential Expression of Bone Morphogenetic Proteins in the Developing Vestibular and Auditory Sensory Organs
}

\author{
Seung-Ha Oh, ${ }^{1}$ Randy Johnson, ${ }^{2}$ and Doris $\mathrm{K} . \mathbf{W u}{ }^{1}$ \\ ${ }^{1}$ National Institute on Deafness and Other Communication Disorders, Rockville, Maryland 20850, and ${ }^{2}$ M. D. Anderson \\ Cancer Center, Department of Biochemistry and Molecular Biology, Houston, Texas 77030
}

The genes responsible for the formation of various sensory organs in the inner ear are not known. There are eight sensory organs in the chick inner ear, and our previous study showed that all presumptive sensory organs initially express bone morphogenetic protein 4 (BMP4), a member of the transforming growth factor (TGF)- $\beta$ gene family. To address the potential role of BMPs in the patterning of different sensory organ structures, we investigated the expression of BMP4, BMP5, and BMP7 during sensory organ differentiation in the chick inner ear. The gene expression pattern of BMP5, although similar to that of BMP4, was transient and disappeared by embryonic day 3.5 (E3.5). In contrast, BMP7 gene expression was quite extensive, starting in the otic placode. By E5, gene expression patterns of BMP4 and BMP7 differed among vestibular and auditory sensory organs. In the vestibular sensory organs, BMP7 gene expression segregated from the main sensory tissue areas at the onset of differentiation, whereas BMP4 expression concentrated in supporting cells. In the cochlea, however, BMP7 gene expression became restricted to sensory tissue over time and eventually concentrated in supporting cells, whereas BMP4 gene expression was localized to hair cells. The different BMP expression patterns in developing auditory and vestibular sensory organs may help to shape each respective sensory structure. Furthermore, the expression of BMP4 in the cochlea also revealed an interesting pattern of sensory cell differentiation: the distal portion of the cochlea differentiates first, and the tall hair cells develop before the short hair cells.

Key words: BMP4; BMP5; BMP7; crista ampullaris; basilar papilla; macula
Bone morphogenetic proteins (BMPs) belong to the decapentaplegic veg-related (DVR) subgroup within the transforming growth factor (TGF)- $\beta$ superfamily (for review, see Kingsley, 1994). In the DVR subgroup, BMPs can be subdivided further into at least two subfamilies, including decapentaplegic (dpp) and 60A. The dpp subfamily includes the Drosophila $d p p$ gene and its mammalian homologs BMP2 and BMP4. The 60A subfamily includes the Drosophila $60 \mathrm{~A}$ gene and its mammalian homologs BMP5, BMP6, BMP7, and BMP8. Genes within the same subfamily are highly conserved and in some cases can substitute for each other functionally (Padgett et al., 1993; Sampath et al., 1993).

The roles of BMPs during embryogenesis are quite extensive, including patterning in Drosophila (Capdevila and Guerrero, 1994; Capovilla et al., 1994), Xenopus (Hawley et al., 1995), and mouse (Vainio et al., 1993; Winnier et al., 1995) embryos. Defects in the BMP5 gene result in the short-ear mutant mice, which exhibit a number of cranial and axial skeletal malformations (Kingsley et al., 1992; King et al., 1994). BMP7-deficient mice

Received April 26, 1996; revised July 24, 1996; accepted July 29, 1996.

We are indebted to the staff in the Biocomputation Center at Ames Research Center, NASA, for their help with ROSS software. We thank Dr. Manning Correia for consultation on the structure of crista ampullaris and Dr. Fabio Nunes in our laboratory for repeating some of the results presented. We also thank Regeneron Pharmaceutical Company for the gift of the chicken BDNF probe; Drs. Connie Cepko, James Battey, Susan Wray, and Daniel Choo for critical reading of this manuscript; and Ms. Mirene Boerner for editing.

Correspondence should be addressed to Doris $\mathrm{K}$. Wu, National Institute on Deafness and Other Communication Disorders, 5 Research Court, Room 2B34, Rockville, MD 20850

Dr. Oh's present address: Department of Otolaryngology, Seoul National University, 28 Yongon-Dong Chono-Gu, Seoul, Korea 110-744.

Copyright (C) 1996 Society for Neuroscience $0270-6474 / 96 / 166463-13 \$ 05.00 / 0$ have defects in kidney, skeletal patterning, and eye formation (Dudley et al., 1995; Luo et al., 1995). Furthermore, it has been postulated that coexpression of different BMPs may have a cooperative function during development (Lyons et al., 1995), based on the expression patterns of different BMPs during embryogenesis. For example, in the limb bud, BMP2, BMP4, and BMP7 are expressed in the apical epidermal ridge, but only BMP2 is in the zone of polarizing activity and BMP4 and BMP7 are in the mesenchyme (Jones et al., 1991; Lyons et al., 1995). Other organs that express more than one type of BMP during development include the allantois, heart, gut, branchial arches, and brain (Lyons et al., 1990, 1995; Jones et al., 1991; Winnier et al., 1995).

The membranous portion of the inner ear is derived from the otocyst. Genes such as Hoxa-1 (Carpenter et al., 1993; Mark et al., 1993), kr (Frohman et al., 1993; Cordes and Barsh, 1994), and FGF-3 (Mansour et al., 1993) are important for the early development of the otocyst; however, the molecular mechanisms that underlie most of the developmental events of the inner ear, including sensory organ formation, are largely unknown. There are eight sensory organs in the chick inner ear. Even though the hair cells that mediate signal transduction in these sensory organs are morphologically similar and all sensory organs are initially positive for BMP4 (Wu and Oh, 1996), the structures of the mature sensory organs themselves are quite distinct from one another. In this report we characterize the gene expression of BMP4, BMP5, and BMP7 during sensory differentiation. We found that BMP5 expression in the otocyst was transient. Because different BMPs may have a cooperative function in development, we compared the gene expression patterns of BMP4 and BMP7 during sensory organ formation. Our results show that the rela- 
TAGGATGAAAACAGTAATAATCGAAAGCAGAGGGGCTTATTCAGAATTGTAATAAAGTCA

AGATATAAGCCTTGCTGATGAGAAGGCAGT TCTAAATTTATTCCATTTCATGTCATCTCT CATTTAAATGTACAGTGTAATGTATATAGCAGCTTTTATTTATTTAAAAGTATATCGTTT CTTTTGTATGAGCAAAATTTCAAAATCATTTAT TTTATGGGTCACCTTACTAAGCAGTAG AACT TCAGAAATGAATTATTT TGAATTGAACGT ACTGGAACCTACGTAATTCCATTTCCG TACTTTAAAGTAAAACCTTTGTACTGACTTTTTTAAAGTTAGTAACTCCGGAACTTCTGT AACTGCTTCATATTGTTTAAAGAACTAAAATACGTT TGGTCATATTGTGCCAATGAAAAC TGTGGAGGGATATT TATT TAGAAAAAGGCACAGAAAAAAAAATAAACAAGACTGCTTGCG GCCGCGAATTCCTGCAGCCCGGGGGATCCACTAGTTCTAGA

B) Chick BMP5 MNLTA : LKAFVGLLWNGWVLVGHAQGGLGDNHVHSSF I YRRLRNHERRE I QRE ILS I LG Mouse BMP5 MHWTVFLLRG I VGFLWSGWVQVGYAKGGLGDNHVHSSF I YRRLRNHERRE I QRE I LS I LG Chick BMP5 LPHRPRPFSPGKOASSAPLFMLDLYNAMTNEEDTEELEYSLKGSMAGESRGMRKGYPASP Human BMP5 LPHRPRPFSPGKQASSAPLFMLDL YNAMTNEENPEESEYSVRASLAEETRGARKGYPASP Chick BMP5 NGYSRR I LSRMTTLATQNPPLASLHDTNF LNDADMVMSFVNLVERDKDFSHQRRHYKEF Mouse BMP5 NGYAHRLHLPPRTPLTTOSPPLASLHDTNF LNDADMVMSFVNLVERDKDFSHQRRHYKEF
Human BMP5 NGYPRAIOLSTTPLTTSPPLASLHDTNF LNDADMVMSFVNLVERDKDFSHQRRYKEF Chick BMP5 RFDLTOIPHGEAVTAAEFR I YKDRSNARFENET I IS I YQI I KEYPNRDADLFLLDTRKA Chick BMP5 RFDLTQ I PHGEAVTAAEFR I YKDRSNGRFENET I I S I YQ I I KEYPNRDADLFLLDTRKA HUMan BMP5 RFDLTQI PHGEAVTAAEF I YKDESNARFENET I KI S I YQII KEYTNRDADLFLLDTRKA Chick BMP5 QASDVGWFV FD I TV TSNHWV I NPQNNLGLQLCAETGDGRS I NVKSAGLDGRHGPQSKQPF Mouse BMP5 QALDVGWL VFD I TV TSNHWV I NPQNNLGLQLCAETGDGR I NVKS AGLVGRHGPQSKQPF Chick BMP5 MVAFFKASEVLFRS VRAANNKRKNONRNKSSSHOESSRMPSVGDYNTSEQKOACKKHELV Mouse BMP5 MVAFFKASEVLLRSVRAS . KRKNONRNKSNSHODPSRMPSAGDYNTSEOKOACKKHELY Human BMP5 MVAFFKASEVLLRS VRAAN KRKNQNRNKSSSHQDSSRMS SVGDYNTSEQKQACKKHELY Chick BMP5 VSFRDLGWQDW I I APEGYAAFYCDGECSFPLNAHMNATNHA I VQTLVHLMFPDHVPKPCC Mouse BMP5 VSFRDLGWQDW I I APEGYAAFYCDGECSFPLNAHMNATNHA I VQTLVHLMFPDHVPKPC

Chick BMP5 APTKLNA I SVLYFDDSSNV I LKKYRNMVVRSCGCH

Mouse BMP5 AP TKLNA
HUM BMPS 
tionship between BMP4 and BMP7 is dynamic and is different in developing auditory and vestibular sensory organs.

\section{MATERIALS AND METHODS}

Embryos. Fertilized White Leghorn eggs (Truslow Farm) were incubated for designated times, and embryos were staged according to Hamburger and Hamilton (1951). Embryos up to embryonic day 5 (E5) were referred to by stages according to Hamburger and Hamilton (1951), because there are multiple stages in a given day during early development; embryos older than E5 were referred to by days only.

PCR amplification. Total RNA from E3 chick otocysts was isolated as described (Chirgwin et al., 1979) and reverse-transcribed to cDNA (Life Technologies, Gaithersburg, MD). The cDNA that was obtained was used in PCR reactions with specific degenerate primers designed to amplify members of TGF- $\beta$ and BMP families (Basler et al., 1993). PCR products of 120 base pair (bp) fragments were subcloned into the Bluescript vector (Stratagene, LaJolla, Ca), and random clones were picked and sequenced.

In situ hybridization. In situ hybridization of whole embryos and frozen sections was performed as described (Wu and Oh, 1996). Embryos older than E12 were first harvested and fixed in $4 \%$ paraformaldehyde, and then the membranous portions of the inner ears were dissected, cryoprotected, and mounted for sectioning. Clones for BMP4, BMP5, and BMP7 were isolated from a stage 22 limb bud library as described (Roberts et al., 1995) and used to generate RNA probes for in situ hybridization (Riddle et al., 1993). The identity of cDNA clones was confirmed by DNA sequencing and compared with the murine and human homologs. The entire coding region of BMP4 and chicken BDNF (Maisonpierre et al., 1992) and the nearly full-length coding region of BMP5 and BMP7 were used to generate RNA probes.

Isolation of chicken BMP5 cDNA clones. From a stage 22 limb bud library (Roberts et al., 1995), a cDNA clone comprising almost the entire coding region of the chick BMP5 was obtained. To complete the identification of the chick BMP5 gene, the remaining $5^{\prime}$ end of the open reading frame was obtained by PCR amplification of plasmid DNA obtained from a random-primed limb bud library (see the following section for details of library construction). All PCR reactions were carried out using pfu Taq polymerase (Boehringer Mannheim, Indianapolis, IN). A $\sim 500 \mathrm{bp}$ fragment was obtained in a PCR reaction using a primer directed against the Bluescript vector (Stratagene) and a BMP5 gene-specific primer directed against the $5^{\prime}$ segment of the cDNA clone. The PCR product was verified as the correct $5^{\prime}$ sequence of chicken BMP5 gene by sequencing. New primers directed against the $5^{\prime}$ untranslated region of the gene were then designed. Another round of PCR amplification was performed using the two BMP5-specific primers (see Fig. 1) with cDNA obtained from E3 otocysts. A PCR product of the predicted size $(\sim 500 \mathrm{bp})$ was subsequently subcloned and sequenced. The sequences obtained from the two separate PCR reactions were identical.

Random-primed library construction. Messenger RNA was isolated from stage 22 limb bud cells using the acid-phenol method followed by poly $\left(\mathrm{A}^{+}\right)$selection (PolyATtract, Promega, Madison, WI). Approximately $4 \mu \mathrm{g}$ of mRNA was reverse-transcribed using random hexamers (160 ng) and Superscript reverse transcriptase (Life Technologies). After second-strand synthesis and incubation with T4 polymerase to generate blunt ends, the double-stranded cDNA was ligated to nonpalindromic BstXI hemiphosphorylated adaptors (Duguid and Dinauer, 1990). Excess adaptors were removed by Sephacryl-400 superfine (Pharmacia, Alameda, CA) chromatography, and the linker-ligated cDNA was then size-fractionated on a $1 \%$ agarose gel to eliminate cDNAs smaller than $700 \mathrm{bp}$. A portion of the size-fractionated cDNA was ligated to Bst XI-cut pDB (a derivative of Bluescript KS; Simon and Tabin, 1993) and transformed into electrocompetent MC1061 cells. Approximately $2 \times 10^{7}$ primary recombinants were obtained that were directly amplified in liquid culture. Plasmid DNA was purified and used for PCR amplification of the $5^{\prime}$ ends of the chicken BMP5 gene.
Three-dimensional reconstruction. Three-dimensional reconstruction of frozen sections was performed as described (Wu and Oh, 1996). Software used for reconstruction was developed in the Biocomputation Center at Ames Research Center, National Aeronautics and Space Administration.

\section{RESULTS}

\section{Identification of BMPs in chick otocyst and isolation of chicken BMP5 cDNA}

Using the RT-PCR technique, we found BMP4, BMP5, BMP6, and BMP7 transcripts in E3 chick otocysts, with BMP7 transcripts being the most abundant. cDNA clones for BMP4, BMP5, and BMP7 were subsequently isolated from a stage 22 limb bud library as described (Roberts et al., 1995). The BMP4 clone comprises the entire open reading frame of the BMP4 gene, whereas the BMP5 and BMP7 clones were nearly full length. The chicken BMP4 (Francis et al., 1994) and BMP7 (Houston et al., 1994) sequences have both been reported previously. The complete sequence and deduced amino acid sequence of the chicken BMP5 cDNA is shown (Fig. 1A) and compared with the human and mouse BMP5 sequences (Fig. $1 B$ ). Detailed characterization of BMP4, BMP5, and BMP7 mRNA distribution was also performed using the in situ hybridization technique.

\section{BMP5 mRNA distribution in the developing inner ear}

The following whole-mount in situ hybridization results were summarized from 69 embryos ranging from stage 8 to 24 (E1-E4) during six experiments. BMP5 mRNA was not detected in the developing inner ear until stage 13 (E2) (Fig. 2A,B, arrowhead). The BMP5 expression was similar to that of BMP4 (Wu and Oh, 1996) and was present mostly in the dorsal and posterior margins of the otic cup (Fig. $2 A, B, I$ ). By stage 16 (E2.5), when the otic cup was closing rapidly to form the otocyst, the BMP5 expression in the posterior rim became restricted to one focus (Fig. 2C, arrowhead), similar to that of BMP4 (Wu and Oh, 1996). In addition, there was a concentration of hybridization signal at the anterodorsal rim (Fig. 2C, arrow), which disappeared after the otocyst was formed (Fig. 2D). The hybridization signal in the posterior otocyst (Fig. 2C,D, arrowhead) also remained only until stage 22 (E3.5, data not shown). This posterior BMP5-positive area overlapped with that of BMP4, based on in situ hybridization performed on adjacent sections of stage 19 (E3) embryos (data not shown). This result indicates that BMP5 was expressed transiently in the primordium that eventually gives rise to the four sensory organs, the posterior crista, cochlea, lagena, and macula neglecta, as described in detail elsewhere (Wu and Oh, 1996). In addition, there was strong BMP5 expression in the first branchial furrow (Fig. $2 D$, arrow), which persisted at least until stage 24 (E4, data not shown). This branchial furrow eventually gives rise to the external auditory meatus.

\section{BMP7 mRNA distribution in the developing inner ear from stage 8 to 24}

The following whole-mount in situ hybridization results were summarized from 80 embryos ranging from stage 8 (E1) to 24 (E4) during eight experiments. Among the three BMPs charac-

\footnotetext{
Figure 1. Nucleotide and deduced amino acid sequence of the chicken BMP5 cDNA and comparison with the human and mouse BMP5 genes. $A$, The sequence of chicken BMP5 cDNA. The in-frame translational stop codon at -63 upstream to the first methionine is indicated in italics. Sequences used to design gene-specific primers in the PCR reactions are underlined. The putative polyA site (AATAAA) is also underlined at the $3^{\prime}$ end. B, Alignment of chicken BMP5 amino acid sequence with that of the human and mouse. Dots indicate gaps introduced to achieve the best alignment. Amino acid residues that are different between species are indicated in reverse boxes. The region of the mature protein is boxed.
} 
terized so far, BMP7 was the earliest one to be expressed in the inner ear. BMP7 mRNA was detected in the otic placode, with concentration in the otic epithelium next to the hind brain (Fig. $2 E$, arrowhead). As the otic placode invaginated to form the otic cup, BMP7 expression concentrated in the dorsal and posterior portions of the otic cup (Fig. $2 F$, arrowhead). This expression pattern in the otic cup (Fig. $2 G$ ), although similar to that of BMP4 (Wu and Oh, 1996, their Fig. 1C) and BMP5 (Fig. 2I), was much broader and stronger than that of the other two. By stage 16 (E2.5), although a small opening remained in the otic cup, the majority of the otic cup seemed to be positive for BMP7 by whole-mount in situ hybridization (Fig. $2 H$ ). Serial sections of this embryo indicated that most of the otic epithelium was positive except for the ventral portion of the otocyst (Fig. $2 J$ ). Hybridization signals were in somewhat of a gradient, with stronger signal at the rim of the otic cup (Fig. 1G,J). The absence of BMP7 mRNA in the ventral area of the otocyst persisted in the anteromedial area of the otocyst at stage 24 (Fig. 3B). Furthermore, starting at stage 8 (otic placode stage) and continuing until stage 23, BMP4- and BMP5-positive areas were always found within a subset of the BMP7-positive region.

\section{Comparison of BMP4 and BMP7 mRNA distribution in the developing inner ear}

Previous data suggest that BMP4 is an early marker for all sensory organs of the inner ear ( $\mathrm{Wu}$ and $\mathrm{Oh}, 1996)$. Because BMP7 expression was activated earlier and showed a more extensive distribution pattern than that of BMP4, the two gene expression patterns were compared during inner ear development. At stage 24 (E4), seven of the eight presumptive sensory organs were identifiable, based on BMP4 mRNA distribution; these included the three cristae, two maculae, and a combined unit of lagena and basilar papilla (four embryos examined). Probing of serial sections of a stage 24 chick otocyst alternately for BMP4 or BMP7 indicated that the majority of the otocyst was positive for BMP7. A three-dimensional reconstruction of such an otocyst is illustrated in Figure 3. BMP7 transcripts were not detected in two regions of a stage 24 otocyst: an anteromedial area (Fig. $3 B$; also see Fig. $7 B$ ) and a dorsolateral area (Fig. 3; see also arrows in Figs. $3 B, D, 6 B$ ). All seven of the presumptive sensory organs positive for BMP4 at this age fell within the BMP7-positive area (Fig. $3 A, B$ ). The exception was a portion of macula utriculi that was included in the negative anteromedial area $(n=2)$. In general, as sensory organs matured, BMP7 expression became segregated from the main sensory tissue areas of the inner ear. Because the relationship between BMP4 and BMP7 gene expression was quite dynamic and differed among various sensory organs, comparison of the two gene expression patterns is presented separately for each sensory organ.

\section{Basilar papilla}

The gene expression patterns of BMP4 and BMP7 in the basilar papilla were different from those of other sensory organs in the inner ear. We demonstrated previously that the presumptive sensory tissue for the papilla develops from a cluster of three other sensory organs: posterior crista, lagena, and macula neglecta $(\mathrm{Wu}$ and Oh, 1996). At E5, a BMP4-positive area in the papilla formed a shape that resembled a $\mathrm{V}$, with a short anterior arm and a longer posterior arm joined ventrally at the lagena (see Fig. $3 B$ in Wu and Oh, 1996). The posterior arm was initially Msx-1-positive and became negative by E6. A three-dimensional reconstruction of an E6.5 inner ear illustrates that the anterior arm has expanded substantially in a dorsal-ventral direction by this age (Fig. $4 A$, fuchsia area). The posterior arm (Fig. $4 A$, red area) has also elongated and expanded laterally as well (the lateral expansion was not shown in Fig. $4 A$, but a portion of the epithelium containing the laterally expanded hybridization signal is shown in Fig. $5 C$, indicated by arrows). In addition, there was a weak BMP4 region (Fig. $4 A$, yellow area) between the two arms. From E7 (Fig. $4 B$ ) to E9 (Fig. $4 C$ ), all three BMP4-positive areas, anterior, posterior, and the weak middle one, continued to elongate, with the $\mathrm{V}$-shaped pattern almost disappearing by $\mathrm{E} 9$ (Fig. $4 C$ ). At E6.5, there was no morphological landmark within the papilla that demarcated the boundaries of these hybridization signals (Fig. $5 C$ ). Only the location of the anterior arm at a more medial and dorsal (superior) position than the posterior arm suggested that this anterior part of the epithelium most likely develops into sensory tissue. By E7, and much more clearly by E9, the histology of the papilla was more distinct. At this point, we found the anterior arm of the BMP4-positive area (Fig. 5E, G, area marked with brackets) located mostly in the tall hair cell region, whereas the weaker BMP4 area (Fig. 5E, G, arrowheads) in the middle was confined to the short hair cell region, and the positive posterior arm (Fig. 5E, G, arrows) was confined to a nonsensory portion of epithelium next to the ventral (inferior) edge of sensory tissue. This BMP4-positive posterior area diminished by E12 and disappeared by E16 (data not shown).

In the papilla, BMP7 gene expression became more restricted to the sensory tissue during differentiation. At E5, the entire papilla was positive for BMP7, including the nonsensory portion (an example of the nonsensory portion of papilla is shown in Fig. $7 D$, indicated by arrows). At E6.5, restriction of BMP7 expression could be observed in the papilla, with the majority of the positive area overlapping with that of BMP4 (compare Fig. $5 A$ with $5 B$ and $5 C$ with $5 D$ ). The similarity in patterns was most obvious in the anterior portion of the papilla (anterior arm of the BMP4-positive area), and the hybridization signals spanned the height of the epithelium (Fig. 5A,B). At E9, BMP7 gene expression remained similar to that of BMP4 (compare Fig. $5 E$ with $5 F$ and $5 G$ with $5 H$ ), except that there was a portion of epithelium within the posterior arm that has a stronger BMP7 expression $(5 F, H$, arrow $)$. This concentration of BMP7 expression was transient, and the identity of these cells is not clear. By E12, BMP4 transcripts were concentrated in hair cells (Fig. 5I), and this pattern was much more evident by E16 (Fig. $5 K$; bracket marks the height of the sensory epithelium). On the other hand, BMP7 transcripts were still distributed across the entire epithelium at E12 (Fig. $5 J$ ) and became restricted to supporting cells by E16 (Fig. 5 L; bracket marks the height of the sensory epithelium). This pattern of BMP4 in hair cells and BMP7 in supporting cells of the papilla remained at least until the eggs hatched.

\section{Ampulla}

As mentioned above, at stage 24 (E4), all three presumptive cristae were positive for BMP4 (Fig. $6 A$ ) and were well within the BMP7-positive area (Fig. $6 B$; see also Fig. 3 for composite). BMP4 transcripts were also present in the mesenchyme surrounding the dorsolateral portion of the inner ear (Fig. 6A). At E5, BMP4 expression in the sensory tissue was interrupted in the middle by the nonsensory tissue known as the cruciatum (Fig. $6 C$, arrowhead). The cruciatum was present only in the superior and posterior cristae but not in the lateral crista (Dohlman, 1964; Landolt et al., 1975). At E5, BMP4 expression in the mesenchyme 

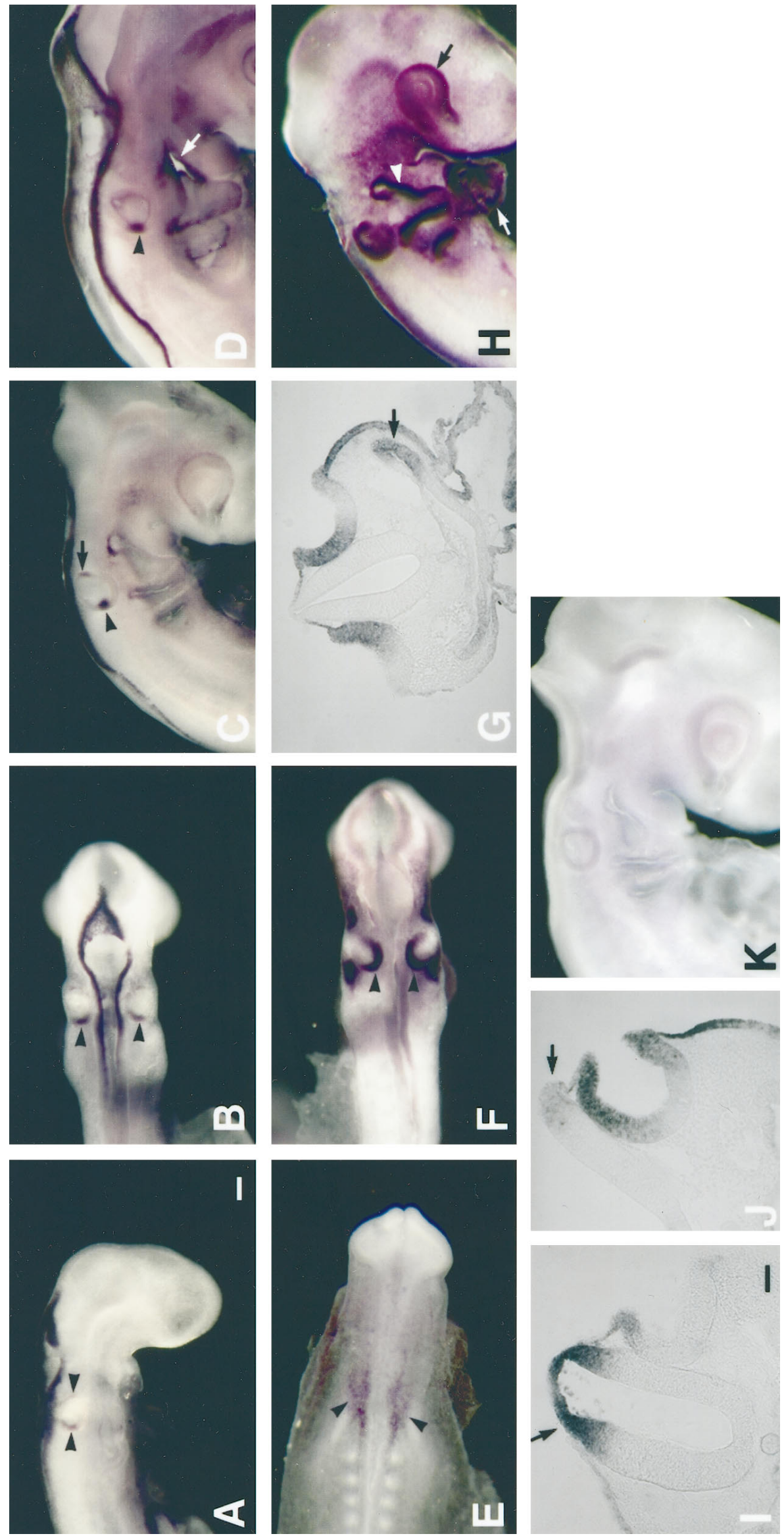

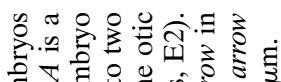

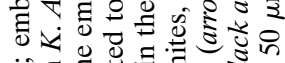

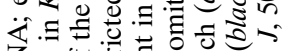

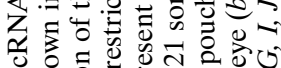

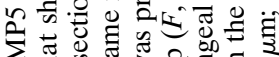

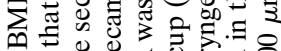

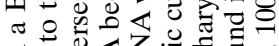
훌

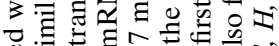

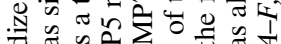

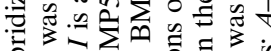

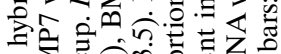
嗐.

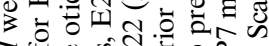

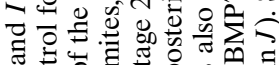

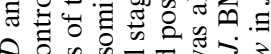
o 을

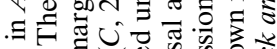
5

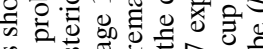

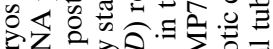

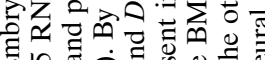

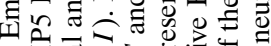

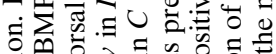

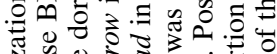

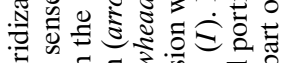

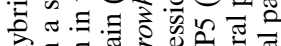
ㄹ. 둡 5. 今 흔

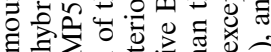
s

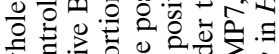
उ $8:$ :

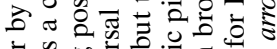
5. . 나의

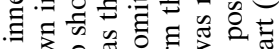

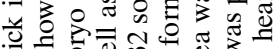
둥

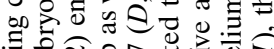

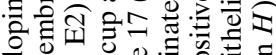
o

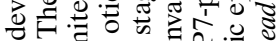
घं हो

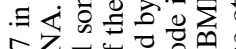
웡 舟 굴 कि

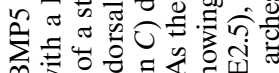
政 5 웡 可

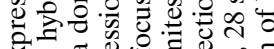

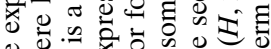

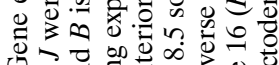

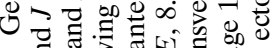
类

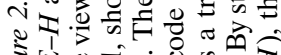

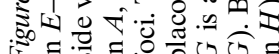



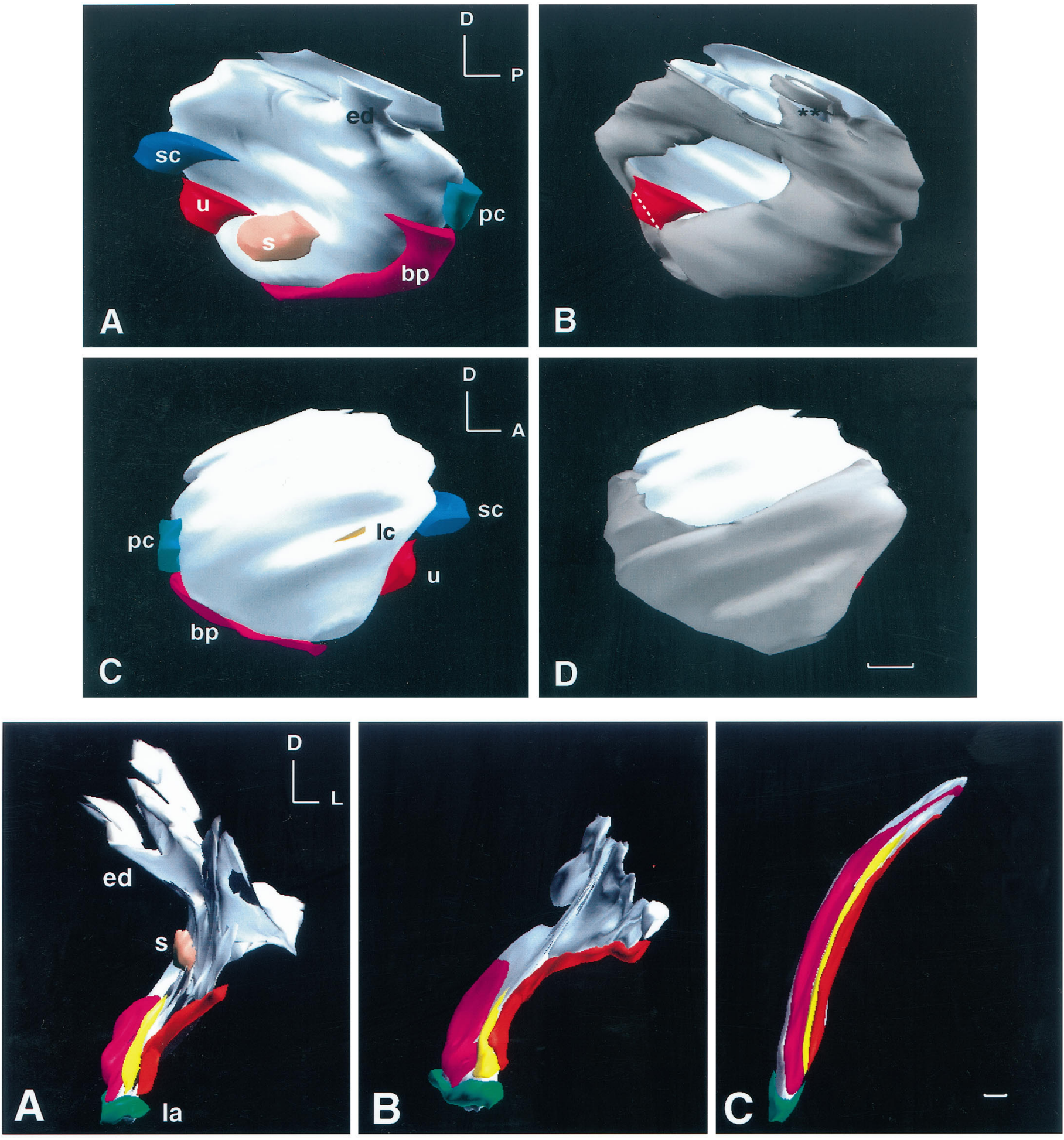

Figure 3. Top. Three-dimensional reconstruction of BMP4 and BMP7 gene expression of a stage 24 (E4) chick otocyst. $A$ and $B$ are medial views and $C$ and $D$ are lateral views of the same otocyst. This otocyst was reconstructed from a total of 44 horizontal, serial cryosections of $12 \mu \mathrm{m}$ thickness. The most dorsal sections of the otocyst were missing, which resulted in a flattened image at the top. All odd-number sections were probed for BMP4, and all even-number sections were probed for BMP7. In $A$ and $C$, all of the BMP4-positive, presumptive sensory organs are shown. Identification of each presumptive sensory organ was as described ( $\mathrm{Wu}$ and $\mathrm{Oh}, 1996)$. The area for the presumptive lateral crista was under-represented in this specimen because of loss of adjacent sections for probing of BMP7 mRNA. In $B$ and $D$, the BMP7-positive region of the otocyst is shown in gray. An anteromedial portion and a dorsolateral portion of the otocyst were negative for BMP7. All presumptive sensory organs were within a subset of the BMP7-positive region, except for a portion of the macula utriculi. The white dotted line demarcates the boundary of the presumptive macula utriculi area that overlapped with BMP7. The area in the endolymphatic apparatus that is marked by asterisks should be positive for BMP7. This gap in BMP7 expression was created by suboptimal alignment of sections in that area. Orientation: $A$, anterior; $D$, dorsal; $P$, posterior. $b p$, Basilar papilla; $e d$, endolymphatic apparatus; $l c$, lateral crista; $s$, macula sacculi; $p c$, posterior crista; $s c$, superior crista; $u$, macula utriculi. Scale bar, $100 \mu \mathrm{m}$. 
persisted, whereas the adjacent otic epithelium also became positive (Fig. 6C, arrows). This BMP4-positive epithelium eventually became the roof of the ampulla (Fig. 6E, G, arrow). In addition, at E5, BMP7 transcripts began to segregate away from the center of sensory tissue (Fig. 6D).

By E7, the crista ampullaris was more differentiated, and BMP4 transcripts were more concentrated in supporting cells of the crista (Fig. 6E, $G$ ). Previous studies showed that brain-derived neurotrophic factor (BDNF) is expressed by hair cells of all sensory organs in the rat inner ear (Pirvola et al., 1992; Ylikoski et al., 1993; Wheeler et al., 1994). Similar results were observed in the chick inner ear (data not shown). Therefore, BDNF serves as a good marker for sensory hair cells, and its mRNA distribution pattern (Fig. $6 H$ ) in the crista was different from that of BMP4 (Fig. 6G). The segregation of BMP7 expression from the crista was more extensive at E7 than at E5. The BMP7-positive (Fig. 6F) area, however, remain overlapped with that of the BMP4 (Fig. $6 E$ ) all around the peripheral portion of the crista (also see Fig. $7 E, F$ for expression patterns in the lateral crista). In addition, at E7, BMP4 expression in the mesenchyme disappeared, but expression in the roof of the ampulla remained until E12 (data not shown).

At E8, the typical dome-shaped morphology of the crista was much more evident. BMP4 transcripts concentrated in supporting cells (Fig. 6I), except at the periphery of the crista where BMP4 mRNA still spanned the entire epithelium (Fig. 6L, bracket). All BMP4 hybridization signals in the ampulla became very weak at E12 and disappeared by E16 (data not shown). At E8, BMP7 transcripts remained concentrated in the side wall of the ampulla, whereas the structure of the planum semilunatum became more defined (Fig. $6 J$ ). In addition, a small portion of the epithelium in the periphery of the crista was positive for BMP7 (Fig. 6M, bracket) and overlapped with that of BMP4 (Fig. 6L, bracket). By E16, the structure of the planum semilunatum was quite evident and remained positive for BMP7 (Fig. 6N, ps). This positive expression persisted at least until E19. In addition, there was some weaker BMP7 hybridization signal in the crista (Fig. 6N, bracket). The positive cells in the crista were most likely hair cells, based on their apical locations within the epithelium and results obtained from probing adjacent sections of the cristae for BMP7 and BDNF (data not shown); however, the BMP7 hybridization signals in the crista were not always consistent. Additional characterization using an antibody specific for BMP7 may help to identify unequivocally these cells in the crista.

The epithelium lining the semicircular canals was also positive for BMP7 at E7, and the hybridization signals eventually disappeared by E12 (data not shown).

\section{Maculae utriculi and sacculi}

An earlier study indicates that the presumptive macula sacculi is generated at stage 20 (E3.5), and the presumptive macula utriculi is generated at stage 24 (E4), based on BMP4 gene expression (Wu and Oh, 1996). The presumptive utriculi was broad and diffuse, located between the presumptive lateral crista and the macula sacculi, ventral to the presumptive superior crista (Fig. $7 \mathrm{~A}$, $u$ ). At stage 24 (E4), the entire presumptive macula sacculi, but only the ventrolateral portion of the macula utriculi, was located within the BMP7-positive area (compare Fig. 7, $A$ and $B$; also see Fig. 3 for composite). It is not clear which portion of the BMP4positive area, the portion that overlapped with BMP7 or the portion that did not, contributed to the mature macula utriculi, or whether they both did. A combination of fate-mapping and in situ hybridization studies may clarify these issues. By E5, adjacent sections probed for BMP4 (Fig. 7C) or BMP7 (Fig. 7D) indicated that BMP7 expression also began to segregate away from the macula sacculi at E5, similar to the pattern noted in the three cristae. Also, by E5, BMP4 expression in the macula utriculi became much more discrete (Fig. $7 C, u$ ). The relationship between BMP4 and BMP7 in the macula utriculi, however, remained similar to the relationship at E4 when only the ventrolateral portion of the BMP4-positive area (Fig. $7 C$ ) overlapped with BMP7 (Fig. 7D). By E7, BMP4 mRNA (Fig. 7E) concentrated in supporting cells of the two maculae, in contrast to that of BDNF (Fig. 7G), which was localized in hair cells. At this age, BMP7 expression in the two maculae was almost absent (Fig. 7F) and was completely gone by E9, unlike BMP7 expression in the crista, which continued to be expressed. As development continued, BMP4 mRNA was undetectable in the macula sacculi by E9 and in the macula utriculi by E12 (data not shown).

\section{Macula neglecta and lagena}

Presumptive lagena is discrete at stage 23 (E4), based on BMP4 and Msx-1 expression (Wu and Oh, 1996). BMP4 transcripts were distributed across the entire sensory epithelium at E6.5 (stage 30, Fig. $5 A$ ) but began to localize in supporting cells at E7 and disappeared by E16 (data not shown). Similar to other vestibular sensory organs such as macular utriculi and sacculi, BMP7 (Fig. $5 B$ ) expression overlapped with that of BMP4 (Fig. $5 A, l a$ ) up to E7 and then disappeared by E9 (data not shown).

BMP4 expression in the macula neglecta is discrete at E6 (stage 29) (Wu and Oh, 1996). Positive hybridization signal became localized to supporting cells at E7 and disappeared by E12. Similar to the other maculae, BMP7 expression in the macula neglecta initially overlapped with that of BMP4 and then segregated from the sensory tissue at E7 and disappeared by E9 (data not shown).

\section{DISCUSSION}

\section{BMP5 gene expression in the inner ear}

BMP5 gene expression in the otocyst, although associated with presumptive sensory areas, was transient. In addition, BMP5 was expressed in the furrow of the first branchial arch, which gives rise to the external auditory meatus. In the chick, the external ear consists of an auditory canal but no pinna. In the mouse, defects in the BMP5 gene cause malformation of the pinna (Kingsley et al., 1992). It is not known whether BMP5 is also expressed during inner ear development in the mouse, or whether the expression pattern is transient, as it is in the chick. Nevertheless, there has been no report of BMP5 mutant mice showing functional deficits in balance or hearing (Green, 1968; King et al., 1994).

Figure 4. Bottom. Three-dimensional reconstruction of BMP4 gene expression in the right basilar papillae at E6.5 $(A)$, E7 $(B)$, and E9 $(C)$, shown from a posteromedial view. The fuchsia color in the medial portion of the basilar papilla represents the strong anterior BMP4-positive area. The yellow and red colors represent the weak and the posterior BMP4-positive areas, respectively. Examples of tissues from these three regions are shown in Figure 5C for E6.5 and in $5 E$ for E9. Orientation: $D$, dorsal; $L$, lateral. $e d$, Endolymphatic apparatus; la, lagena; $s$, macula sacculi. Scale bar, $100 \mu \mathrm{m}$. 


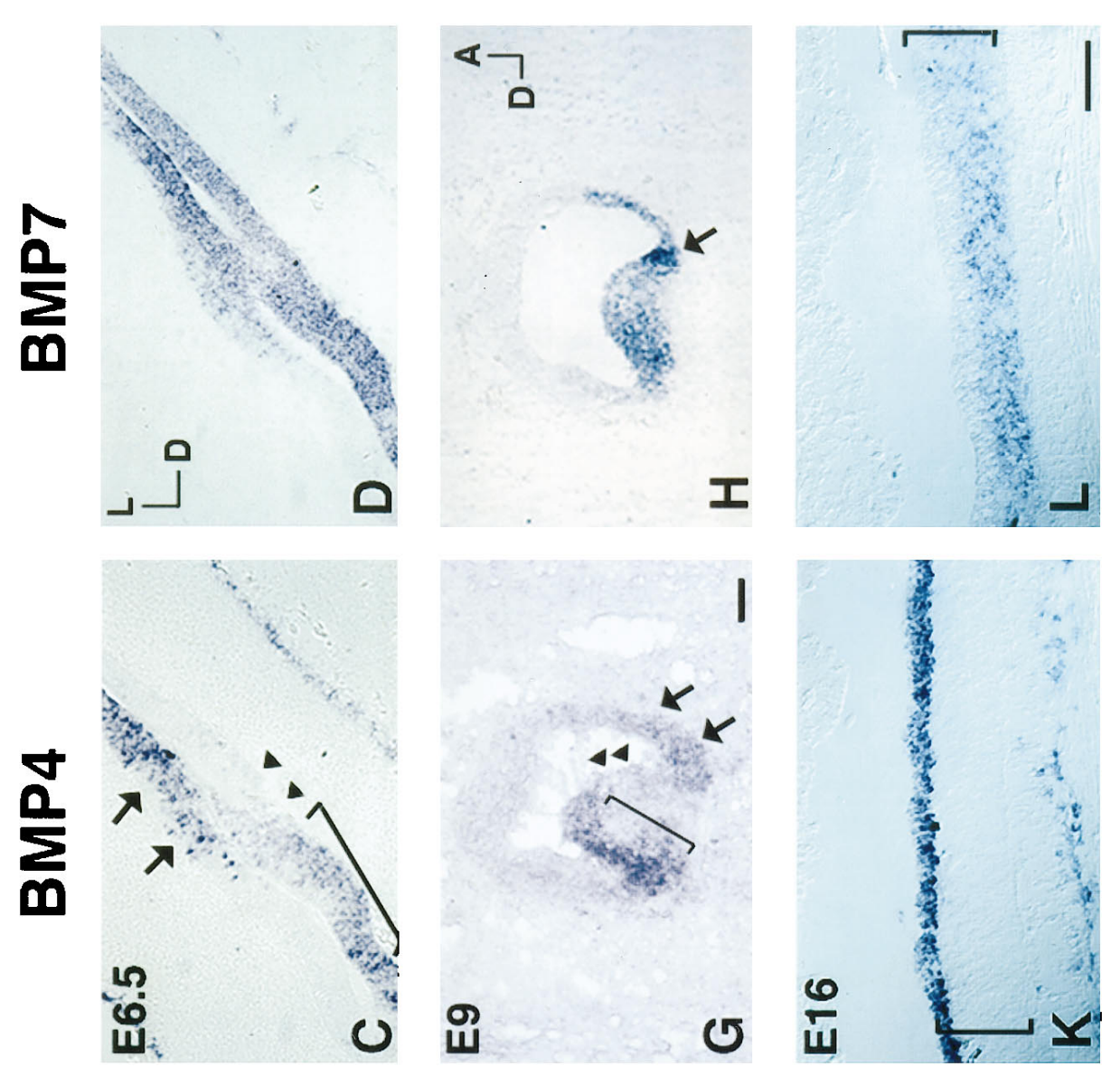

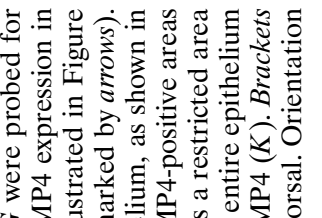

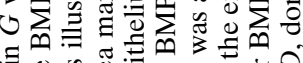

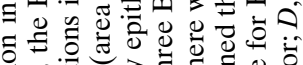

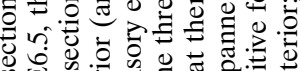

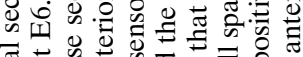

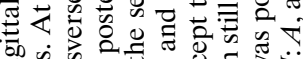

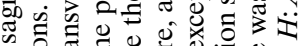

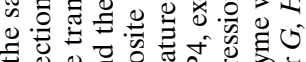

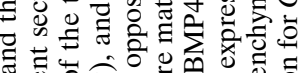

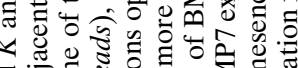

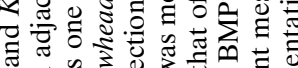

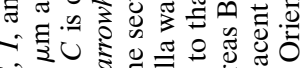

40

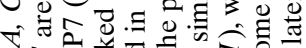

$\Xi \sum_{0}$

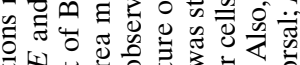

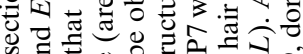

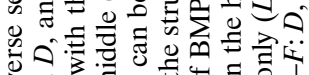

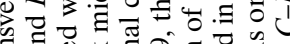

동

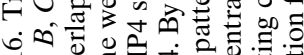

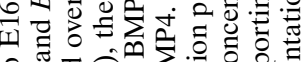

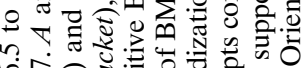

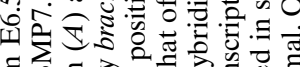
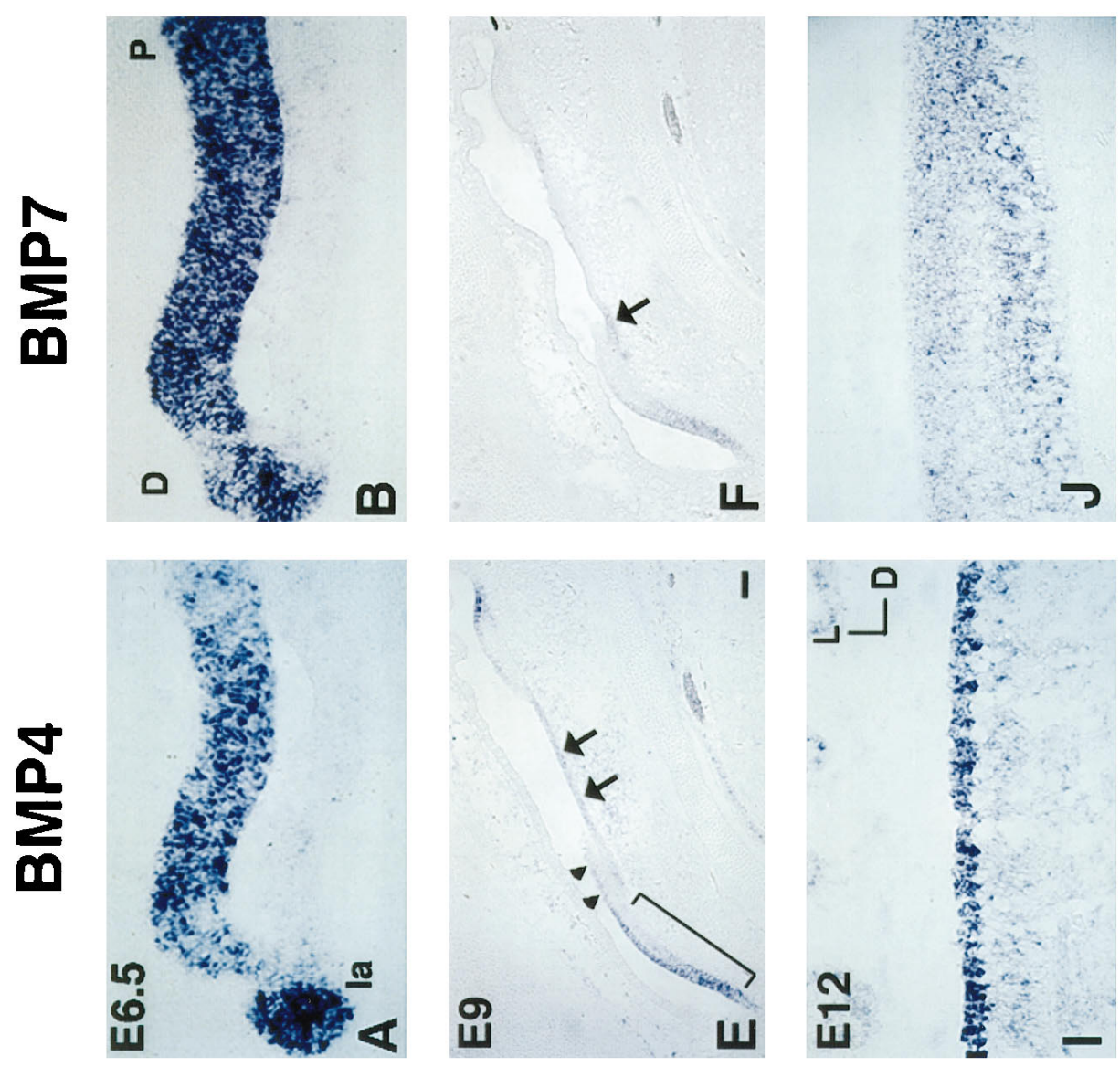

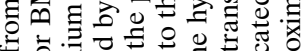

ษ

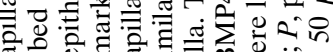

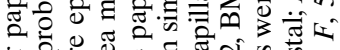

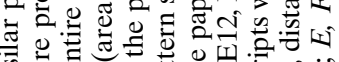

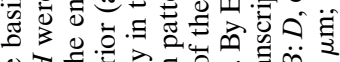

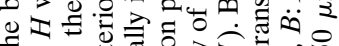

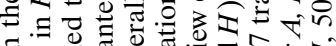

.

छ.

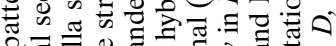

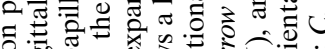

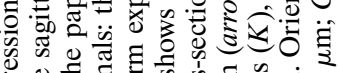

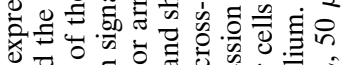
ช

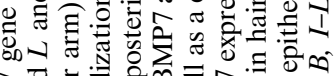

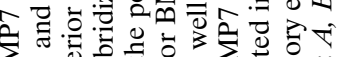

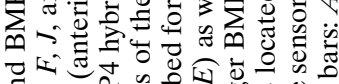

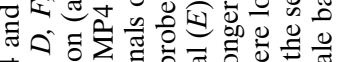

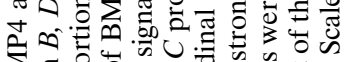

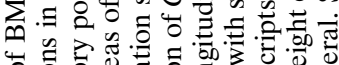

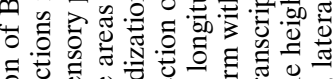

రี

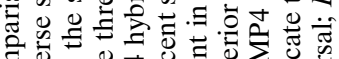

ठิ

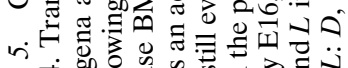

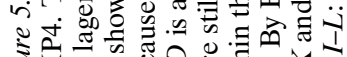

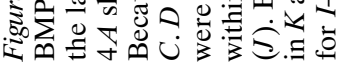



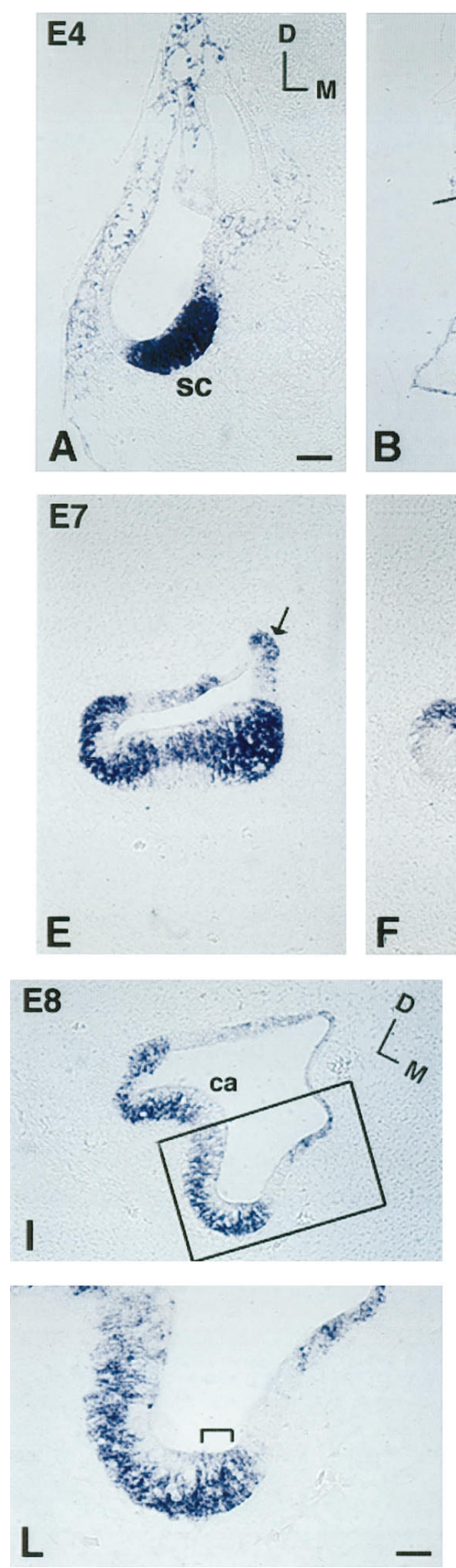
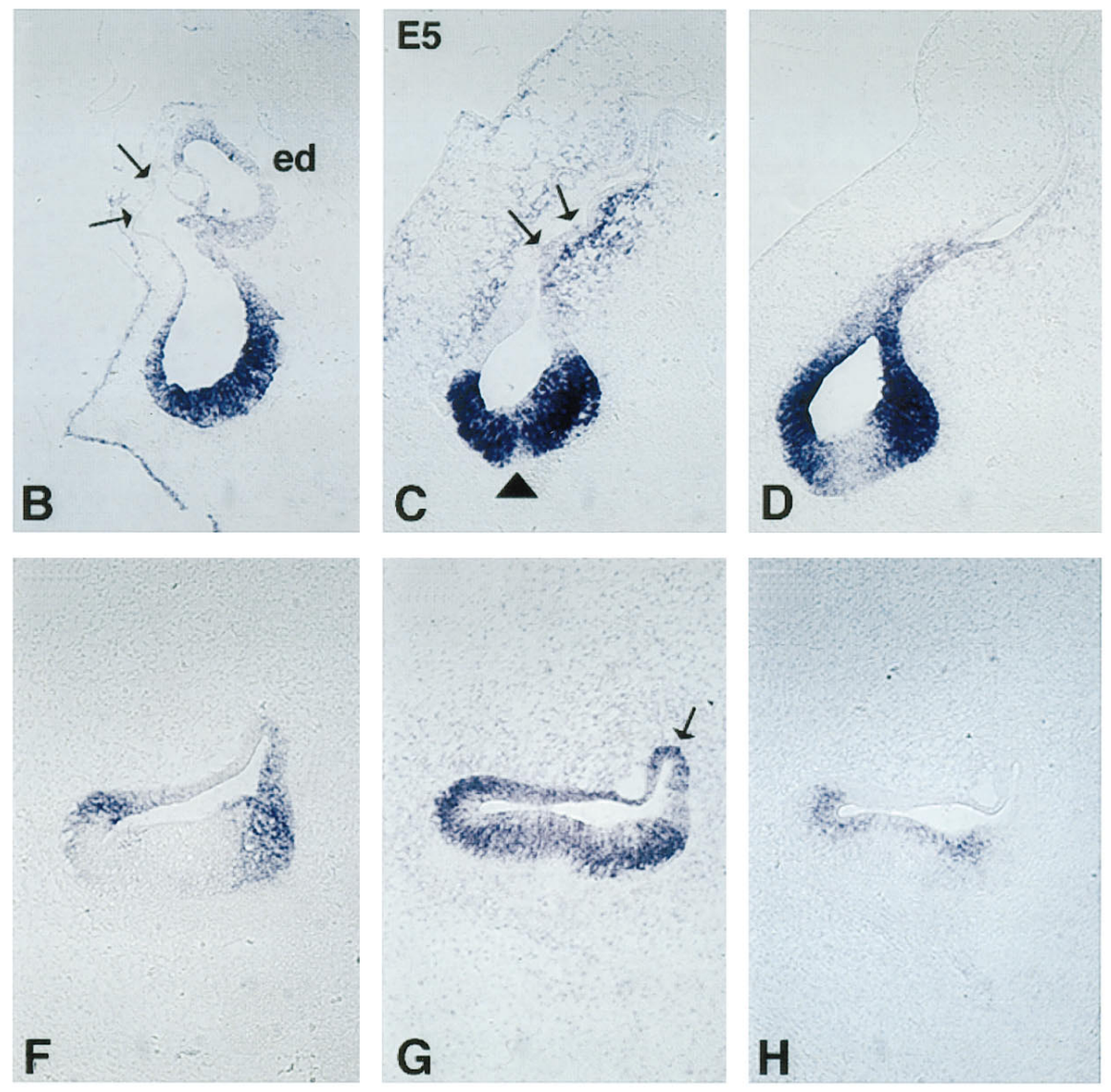

\section{E16}

J

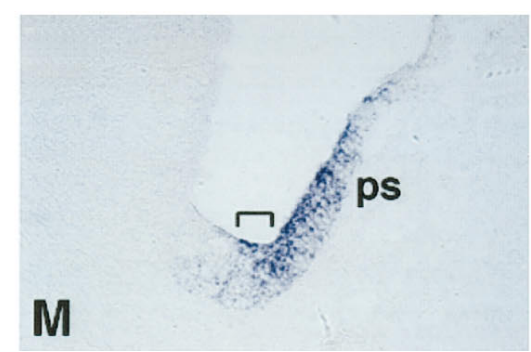

prisaserice

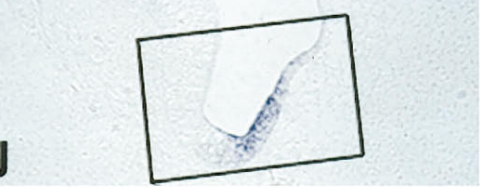

K

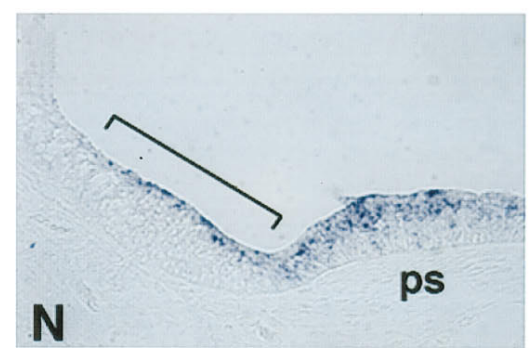

Figure 6. Comparison of BMP4 and BMP7 gene expression patterns in superior crista ampullaris from E4 to E16. $A$ and $B, C$ and $D, E$ and $F, G$ and $H$, and $I$ and $J$ are pairs of adjacent $12 \mu \mathrm{m}$ sections. Sections shown in $A, C, E, G$, and $I$ were probed for BMP4; $B, D, F, J$, and $K$ were probed for BMP7; and $H$ was probed for BDNF. $A$ and $B$ were sections from stage 24 (E4) embryos; $C$ and $D$ from E5; $E-H$ from E7; $I, J, L, M$ from E8; and $K, N$ from E16. At E4, $(A)$ BMP4- and (B) BMP7-positive areas overlapped in the presumptive crista $(s c)$. Arrows in $B$ point to the thin epithelium at the dorsolateral portion of the otocyst that was negative for BMP7. By E5, BMP7 $(D)$ has begun to segregate from the presumptive sensory area. Arrowhead in $C$ points to the cruciatum that was negative for BMP4. The arrow points to the part of the otic epithelium with weak BMP4 expression next to the strong expression in the surrounding mesenchyme. This weak epithelial signal became the positive signal in the roof of the ampulla by E7 (arrow in $E$, $G$ ). At E7, BMP7 expression was restricted mostly to the nonsensory portion of the ampulla $(F)$. On the other hand, the BMP4-positive area within the crista concentrated in supporting cells $(E, G)$ rather than in hair cells, as contrasted by the pattern of BDNF expression $(H)$. The areas within the rectangles in $I, J$, and $K$ are enlarged in $L, M$, and $N$, respectively. BMP4 transcripts spanned the entire epithelium in one area of the ampulla (bracket in $L)$, and this area was also positive for BMP7 (bracket in $M$ ). By E16, positive hybridization was found in the planum semilunatum ( $p s$ ) and the crista ampullaris (bracket in $N$ ). Orientation: $D$, dorsal; $M$, medial. Refer to orientation axis in $A$ for $B-H$ and orientation axis in $I$ for $J-N$. $c a$, Crista ampullaris; $e d$, endolymphatic apparatus; $s c$, superior crista; $p s$, planum semilunatum. Scale bars: $A-J, 100 \mu \mathrm{m} ; K, 200 \mu \mathrm{m} ; L-N, 25 \mu \mathrm{m}$. 


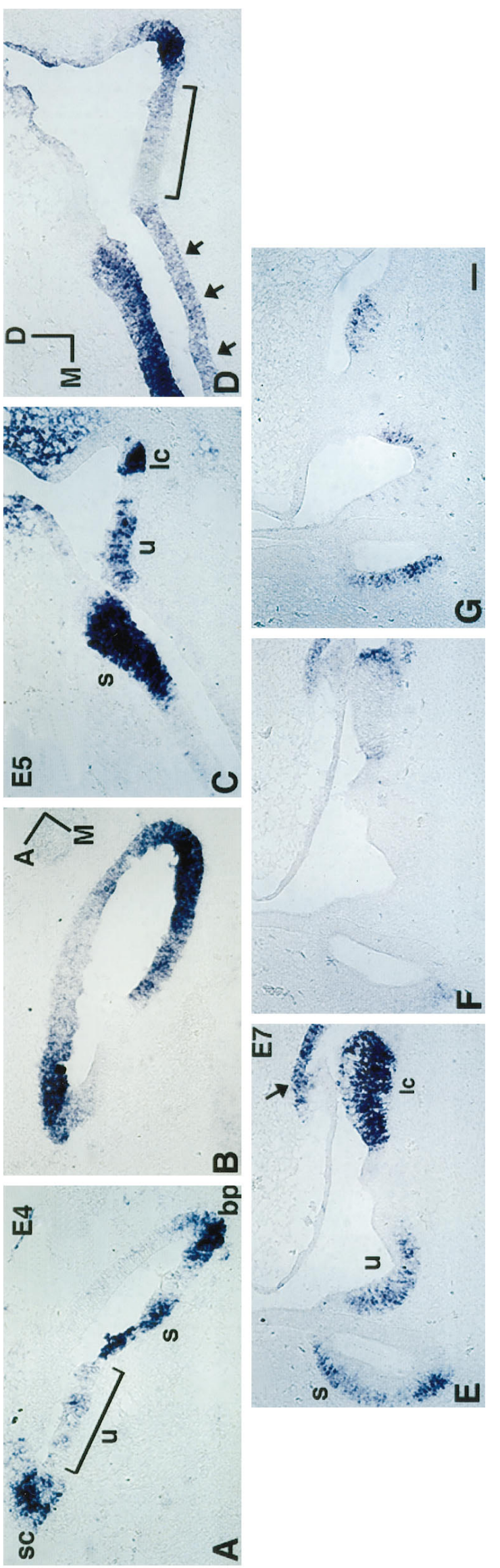

তृ: 을

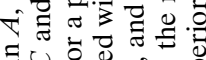

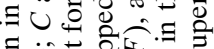
定 जी है

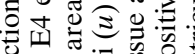

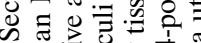

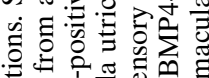
为 牙沽

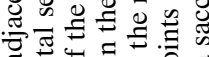

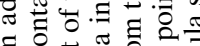
罗. 고구요

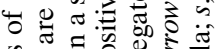

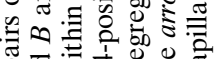

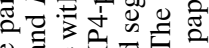
ज ए

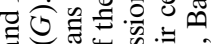

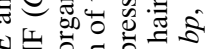

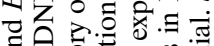

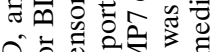

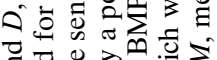

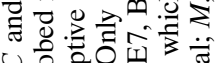

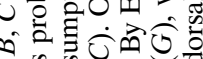

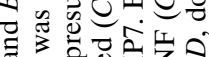

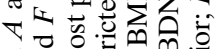

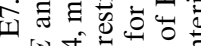

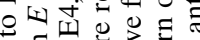

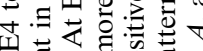
踏

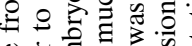

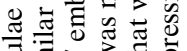
를

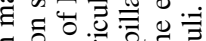
ヨ.

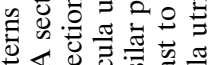

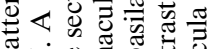

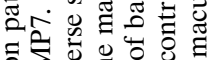

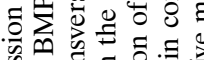
3. 웅 了。

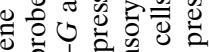

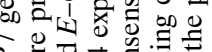

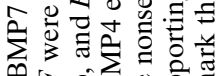

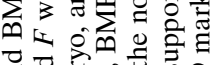
च 可

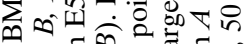

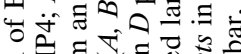

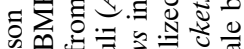

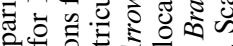
㩆 o

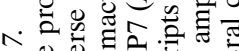

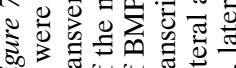
(1) 


\section{BMP4 and 7 gene expression in the otocyst up to E4}

Thus far, among all of the different BMP genes that we have characterized in the chick inner ear, BMP7 was the earliest one to be expressed, starting in the otic placode. By E4 (stage 24), the majority of the otocyst was positive for BMP7, including the presumptive sensory organs, except for part of the macula utriculi. At this age, there are two BMP7-negative areas within the otocyst: an anteromedial area and a dorsolateral area. It is not know whether the BMP7-negative anteromedial area is associated with any particular structure in the mature inner ear; however, the dorsolateral area normally gives rise to the semicircular canals. By E7, when semicircular canals were formed, the epithelia of the canals became positive for BMP7 (data not shown).

Within the BMP7-positive area, subsequent gene expression of BMP7 showed different patterns, depending on whether that portion of tissue was vestibular or auditory (which is discussed below).

\section{BMP4 and BMP7 gene expressions in the basilar papilla}

Our previous study (Wu and Oh, 1996) indicates that BMP4 gene expression in the basilar papilla started out as a V-shape at E5. In this report, we demonstrated that as development continued, the portion of papilla within the anterior arm of BMP4 expression expanded dorsoventrally, whereas the posterior arm elongated and expanded laterally. The location of the short anterior arm in the papilla corresponded mostly to the sensory tissue; however, the laterally expanded posterior arm included some nonsensory tissue at the inferior edge. It is not clear whether any part of the posterior arm contributed to the sensory tissue proper. In addition, the nature of the otic epithelium marked by the weak BMP4 area, which was located between the anterior and posterior arms, was also not clear. Based on the three-dimensional reconstruction data, the weak BMP4-positive area in the middle seemed to be a lateral expansion of the anterior arm, and its location corresponded to that of the short hair cells. The purpose of the three-dimensional reconstructed models was to reveal a possible pattern that may not be apparent when sections alone are analyzed. Because there were no histological landmarks or other molecular markers that facilitated the identification of each of the BMP4 components, assignment of a strong anterior or a weak middle hybridization signal was subjective at times. Based on the BMP4 expression pattern in the papilla from E5 to E9, however, two hypotheses may be proposed for sensory tissue development in the papilla. First, sensory tissue in the distal portion of the papilla should be the first area to undergo differentiation, because early restriction of BMP4 gene expression may be correlated with early histological differentiation (Wu and Oh, 1996). Subsequent sequence of differentiation, however, may not necessarily follow a distal-to-proximal gradient. Second, tall hair cells should also differentiate before the short hair cells, because at E9, BMP4 expression in the short hair cell area was weaker than in the tall hair cell area, and by E16, all hair cells were uniformly expressing BMP4. Indeed, positive hair cell-specific antigen staining was first detected in the distal portion of the papilla, which suggests a distal-to-proximal differentiation gradient in the papilla (Bartolami et al., 1991). Furthermore, the first hair cells to form stereocilia were also located in the distal portion of the papilla (Cotanche and Sulik, 1983, 1984). The histo-differentiation of the basilar papilla is complex. Different criteria and landmarks have been used to determine the timing and sequence of differentiation along the basilar papilla, and not all criteria that have been used fit the distal-to-proximal gradient of differentiation as in stereocilia formation (for review see, Cohen and Cotanche, 1992). In general, however, tall hair cells are thought to differentiate before short ones (Fermin and Cohen, 1984), which also supports our latter prediction.

BMP7 gene expression in the auditory component of the inner ear was quite different from that of the vestibular portion. Instead of segregating away from the sensory tissues, BMP7 gene expression became restricted to the sensory tissue in the papilla as development continued. Later in development, BMP7 was expressed only in supporting cells of the basilar papilla, whereas BMP4 localized to hair cells. During this period of segregation, from E12 to E16, the basilar papilla exhibits the spatula shape of a mature papilla (Cotanche and Sulik, 1985), and hair cell generation is complete (Katayama and Corwin, 1989, 1993); however, the patterning of stereocilia on individual hair cells is still continuing and so is the process of synaptogenesis (Fermin and Cohen, 1984; Whitehead and Morest, 1985). It is not clear whether the segregation of the BMP expression is a necessary step in any of these differentiation processes; however, segregation is correlated temporally with the actual differentiation process rather than the initiation or completion of overall differentiation.

\section{BMP4 and BMP7 gene expression in the vestibular organs}

In the vestibular portion of the inner ear, BMP7 gene expression segregated from the sensory tissue proper as sensory organs started to differentiate. For example, in the superior crista, the segregation of BMP7 from the main sensory area at E5 coincided with the beginning of histological differentiation (Knowlton, 1967) and the onset of a hair cell-specific antigen expression (Bartolami et al., 1991). By the time BMP4 became restricted to supporting cells at E7, however, hair cell differentiation (Ginzberg and Gilula, 1979; Anniko, 1983) and synaptogenesis (Ginzberg and Gilula, 1980; Anniko, 1983) were well underway. Later in development, BMP7 expression persisted in the crista but was absent from other vestibular sensory organs.

\section{Relationship of BMP4 and BMP7 coordinate expression in the inner ear}

At the moment, we do not know the functions of these BMPs in the inner ear, nor do we know the significance of different BMP gene expression patterns among auditory and vestibular sensory organs. Nevertheless, these various expression patterns may contribute to the ultimate difference in structures and functions of the sensory organs. Functions that have been ascribed to the TGF- $\beta$ gene family include antiproliferation, differentiation, and apoptosis, as well as others (for review, see Massague, 1990). Because BMP4 and BMP7 gene transcription was active from the otic placode stage to the stage of hair cell differentiation and later, it is difficult to propose one single function for either gene product. Their functions most likely are multiple and dependent on the responding cell types and the context of other interacting genes within these cells. Although the BMP4-deficient mice are early embryonic lethals (Winnier et al., 1995) and cannot serve as a model for investigating functions of BMP4 in inner ear development, the BMP7-deficient mice (Dudley et al., 1995; Luo et al., 1995) survive until after birth and may provide some insight into its function in the inner ear. Preliminary studies suggest that the early expression of BMP7 in the mouse otocyst is similar to that in the chick (our unpublished observation). 
Another question concerning BMP function is whether specific coordination among different BMPs is required to bring about normal morphogenesis of the inner ear. During embryogenesis, BMP4 and BMP7 were colocalized in many tissues, such as the allantois, apical epidermal ridge, and mesenchyme of limb bud (Jones et al., 1991; Lyons et al., 1995). It has been postulated that cooperation among different BMPs may be important in mediating tissue development (Lyons et al., 1995). Interestingly, heterodimers of BMP4 and BMP7 were more potent in inducing ectopic cartilage and bone than were the corresponding homodimers in vitro (David Israel and Vicki Rosen, personal communication). In the inner ear, several BMPs were colocalized within the presumptive sensory areas initially and then segregated into different cell types as sensory organs matured. It is not known whether the different BMPs serve a redundant function(s) or whether coordinate expression of different BMPs within the presumptive sensory tissues serves an additional role or a coordinating role or both. It will be interesting to investigate whether some of these patterns of BMP gene expression are recapitulated during hair cell regeneration. Also, future studies will focus on the consequences of perturbation of the normal patterns of gene expression during sensory differentiation, using avian retroviral vectors for misexpression.

\section{REFERENCES}

Anniko M (1983) Embryonic development of vestibular sense organs and their innervation. In: Development of auditory and vestibular system (Romand RS, ed), pp 375-424. New York: Academic.

Bartolami S, Goodyear R, Richardson G (1991) Appearance and distribution of the $275 \mathrm{kDa}$ hair-cell antigen during development of the avian inner ear. J Comp Neurol 314:777-788.

Basler K, Edlund T, Jessell TM, Yamada T (1993) Control of cell pattern in the neural tube: regulation of cell differentiation by dosalin-1, a novel TGF $\beta$ family member. Cell 73:687-702.

Capdevila J, Guerrero I (1994) Targeted expression of the signalling molecule decapentaplegic induces pattern duplications and growth alterations in Drosophila wings. EMBO J 13:4459-4468.

Capovilla M, Brandt M, Botas J (1994) Direct regulation of decapentaplegic by ultrabithorax and its role in Drosophila midgut morphogenesis. Cell 76:461-475.

Carpenter EM, Goddard JM, Chisaka O, Manley NR, Capecchi MR (1993) Loss of Hox-a1 (Hox-1.6) function results in the reorganization of the murine hindbrain. Development 118:1063-1075.

Chirgwin JM, Przbyla AE, MacDonald RJ, Rutter WJ (1979) Isolation of biologically active ribonucleic acid from sources enriched in ribonucleases. Biochemistry 18:5294-5299.

Cohen GM, Cotanche DA (1992) Development of the sensory receptors and their innervation in the chick cochlea. In: Development of auditory and vestibular systems, Vol 2 (Romand AL, ed), pp 101-138. New York: Elsevier.

Cordes SP, Barsh GS (1994) The mouse segmentation gene kr encodes a novel basic domain-leucine zipper transcription factor. Cell 79:1025-1034.

Cotanche DA, Sulik KK (1983) Early differentiation of hair cells in the embryonic chick basilar papilla: a preliminary report. Arch Otorhinolaryngol 237:191-195.

Cotanche DA, Sulik KK (1984) The development of stereociliary bundles in the cochlear duct of chick embryos. Dev Brain Res 16:181-193.

Cotanche DA, Sulik KK (1985) Parameters of growth in the embryonic and neonatal chick basilar papilla. Scanning Electron Microsc 1:407-417.

Dohlman G (1964) Secretin and absorption of endolymph. Ann Otol Rhinol Laryngol 73:708-723.

Dudley AT, Lyons KM, Robertson EJ (1995) A requirement for bone morphogenetic protein-7 during development of the mammalian kidney and eye. Gene Dev 9:2795-2807.

Duguid JR, Dinauer MC (1990) Library subtraction of in vitro cDNA libraries to identify differentially expressed genes in scrapie infection. Nucleic Acids Res 18:2789-2792.
Fermin CD, Cohen GM (1984) Developmental gradients in the embryonic chick's basilar papilla. Acta Otolaryngol 97:39-51.

Francis PH, Richardson MK, Brickell PM, Tickle C (1994) Bone morphogenetic proteins and a signalling pathway that controls patterning in the developing chick limb. Development 120:209-218.

Frohman MA, Martin GR, Corder SP, Halamek LP, Barsh GS (1993) Altered rhombomere-specific gene expression and hyoid bone differentiation in the mouse segmentation mutant, kreisler (kr). Development 117:925-936.

Ginzberg RD, Gilula NB (1979) Modulation of cell junctions during differentiation of the chicken otocyst sensory epithelium. Dev Biol 68:110-129.

Ginzberg RD, Gilula NB (1980) Synaptogenesis in the vestibular sensory epithelium of the chick embryo. J Neurocytol 9:405-424.

Green M (1968) Mechanism of the pleiotropic effects of the short-ear mutant gene in the mouse. J Exp Zool 167:129-150.

Hamburger V, Hamilton H (1951) A series of normal stages in the development of the chick embryo. J Morphol 88:49-52.

Hawley SH, Wunnenberg-Stapleton K, Hashimoto C, Laurent MN, Watabe T, Blumberg BW, Cho KWY (1995) Disruption of BMP signals in embryonic Xenopus ectoderm leads to direct neural induction. Genes Dev 9:2923-2935.

Houston B, Thorp BH, Burt DW (1994) Molecular cloning and expression of bone morphogenetic protein-7 in the chick epiphyseal growth plate. J Mol Endocrinol 13:289-301.

Jones MC, Lyons KM, Hogan BLM (1991) Involvement of bone morphogenetic protein-4 (BMP-4) and Vgr-1 in morphogenesis and neurogenesis in the mouse. Development 111:531-542.

Katayama A, Corwin JT (1989) Cell production in the chicken cochlea. J Comp Neurol 281:129-135.

Katayama A, Corwin JT (1993) Cochlear cytogenesis visualized through pulse labeling of chick embryos in culture. J Comp Neurol 333:28-40.

King JA, Marker PC, Seung KJ, Kingsley DM (1994) BMP5 and the molecular, skeletal, and soft-tissue alterations in short ear mice. Dev Biol 166:112-122.

Kingsley DM (1994) The TGF- $\beta$ superfamily: new members, new receptors, and new genetic tests of function in different organisms. Genes Dev 8:133-146.

Kingsley DM, Bland AE, Grubber JM, Marker PC, Russell LB, Copeland NG, Jenkins NA (1992) The mouse short ear skeletal morphogenesis locus is associated with defects in a bone morphogenetic TGF $\beta$ superfamily. Cell 71:399-410.

Knowlton VY (1967) Correlation of the development of membranous and bony labyrinths, acoustics ganglia, nerves, and brain centers of the chick embryos. J Morphol 121:179-208.

Landolt JP, Correia MJ, Young ER, Cardin RPS, Sweet RC (1975) A scanning electron microscopic study of the morphology and geometry of neural surfaces and structures associated with the vestibular apparatus of the pigeon. J Comp Neurol 159:257-288.

Luo G, Hofmann C, Bronckers ALJJ, Sohocki M, Bradley A, Karsenty G (1995) BMP-7 is an inducer of nephrogenesis, and is also required for eye development and skeletal patterning. Genes Dev 9:2808-2820.

Lyons KM, Pelton RW, Hogan BLM (1990) Organogenesis and pattern formation in the mouse: RNA distribution patterns suggest a role for bone morphogenetic protein-2A (BMP-2A). Development 109:833-844.

Lyons KM, Hogan BLM, Robertson EJ (1995) Colocalization of BMP 7 and BMP 2 RNAs suggests that these factors cooperatively mediate tissue interactions during murine development. Mech Dev 50:71-83.

Maisonpierre PC, Belluscio L, Conover JC, Yancopoulos GD (1992) Gene sequences of chicken BDNF and NT-3. DNA Sequence 3:49-54.

Mansour SL, Goddard JM, Capecchi MR (1993) Mice homozygous for a targeted disruption of the proto-oncogene int-2 have developmental defects in the tail and inner ear. Development 117:13-28.

Mark M, Lufkin T, Vonesch J-L, Ruberte E, Olivo J, Dolle P, Gorry P, Lumsden A, Chambon P (1993) Two rhombomeres are altered in Hoxa-1 mutant mice. Development 119:319-338.

Massague J (1990) The transforming growth factor- $\beta$ family. Annu Rev Cell Biol 6:597-641.

Padgett RW, Wozney J, Gelbart WM (1993) Human BMP sequences can confer normal dorsal-ventral patterning in the Drosophila embryo. Proc Natl Acad Sci USA 90:2905-2909.

Pirvola U, Ylikoski J, Palgi J, Lehtonen E, Arumae U, Saarma M (1992) Brain-derived neurotrophic factor and neurotrophin 3 mRNAs in the 
peripheral target fields of developing inner ear ganglia. Proc Natl Acad Sci USA 89:9915-9919.

Riddle RD, Johnson RL, Laufer E, Tabin C (1993) Sonic hedgehog mediates the polarizing activity of the ZPA. Cell 75:1401-1416.

Roberts DJ, Johnson RL, Burke AC, Nelson CE, Morgan BA, Tabin C (1995) Sonic hedgehog is an endodermal signal inducing Bmp-4 and Hox genes during induction and regionalization of the chick hindgut. Development 121:3163-3174.

Sampath TK, Rashka KE, Doctor JS, Tucker RF, Hoffmann FM (1993) Drosophila transforming growth factor beta superfamily proteins induce endochondral bone formation in mammals. Proc Natl Acad Sci USA 90:6004-6008.

Simon H-G, Tabin CJ (1993) Analysis of Hox-4.5 and Hox-3.6 expression during newt limb regeneration: differential regulation of paralogous Hox genes suggest different roles for members of different Hox clusters. Development 117:1397-1407.
Vainio S, Karavanova I, Jowett A, Thesleff I (1993) Identification of BMP-4 as a signal mediating secondary induction between epithelial and mesenchymal tissues during early tooth development. Cell 75:45-58.

Wheeler EF, Bothwell M, Schecterson LC, von Bartheld CS (1994) Expression of BDNF and NT-3 mRNA in hair cells of the organ of Corti: quantitative analysis in developing rats. Hear Res 73:46-56.

Whitehead MC, Morest DK (1985) The development of innervation patterns in the avian basilar papilla. Neuroscience 14:255-276.

Winnier G, Blessing M, Labosky PA, Hogan BLM (1995) Bone morphogenetic protein- 4 is require for mesoderm formation and patterning in the mouse. Genes Dev 9:2105-2116.

Wu DK, Oh SH (1996) Sensory organ generation in the chick inner ear. J Neurosci 16:0000-0000.

Ylikoski J, Pirvola U, Moshnyakov M, Palgi J, Arumae U, Saarma M (1993) Expression patterns of neurotrophin and their receptor mRNAs in the rat inner ear. Hear Res 65:69-78. 